\title{
SELEC̣ÃO E USO DO LIVRO DIDÁTICO: UM ESTUDO COM PROFESSORES DE CIÊNCIAS NA REDE DE ENSINO MUNICIPAL DE FLORIANÓPOLIS
}

\begin{abstract}
RESUMO: No presente artigo, investigamos aspectos relacionados à seleção e ao uso do livro didático de Ciências por professores de escolas municipais de Florianópolis. Apresentamos e discutimos informações referentes às impressões dos docentes sobre o livro didático de Ciências, colhidas em entrevistas semiestruturadas com oito professores participantes, sujeitos deste estudo. Esta pesquisa é de natureza qualitativa, e os resultados apontam que, no grupo de docentes entrevistados, o professor de Ciências é o responsável pela escolha do livro didático na rede municipal de ensino de Florianópolis, a seleção do livro é feita em função da proposta curricular do município e do projeto político-pedagógico da escola, e os docentes consideram-se satisfeitos com a forma como selecionam e utilizam o livro didático em seus trabalhos.
\end{abstract}

Palavras-chave: Livro didático. Ensino de Ciências. Professores. Ensino Fundamental.

\section{SELECCIÓN Y USO DEL LIBRO DE TEXTO: UN ESTUDIO CON MAESTROS DE CIENCIAS NATURALES DE LA RED DE ENSEÑANZA MUNICIPAL DE FLORIANÓPOLIS}

RESUMEN: En este artículo investigamos aspectos relacionados con la selección y con el uso del libro de texto de ciencias naturales por maestros de escuelas municipales de Florianópolis. Presentamos y discutimos informaciones referentes a las impresiones de ocho maestros, sujetos del estudio, respecto del libro de texto de ciencias naturales, tomadas en entrevistas semiestructuradas. Esa investigación es de naturaleza cualitativa y sus resultados apuntan que, en el grupo de entrevistados, el maestro de ciencias naturales es el responsable por la elección del libro de texto en la red municipal de enseñanza de Florianópolis. La selección del libro se hace de acuerdo con la propuesta curricular de la ciudad y con el proyecto político pedagógico de la escuela. Ellos consideran satisfactoria sus maneras de selección y utilización del libro de texto en sus trabajos.

Palabras clave: Libro de texto. Enseñanza de las ciencias. Maestros. Enseñanza Fundamental.

\author{
Marcelo D'Aquino Rosa* \\ Adriana Mohr**
}

*Universidade Estadual de Campinas, Campinas, São Paulo, Brasil. Mestre em Educação Científica e Tecnológica (Universidade Federal de Santa Catarina). Doutorando no Programa de Pós-graduação Multiunidades em Ensino de Ciências e Matemática - Universidade Estadual de Campinas. Grupo FORMAR Ciências - Estudo e Pesquisa em Formação de Professores da Área de Ciências. E-mail: marcelodaquino87@gmail.com

** Universidade Federal de Santa Catarina, Florianópolis, Santa Catarina, Brasil. Doutora em Educação (Universidade Federal de Santa Catarina). Professora no Departamento de Metodologia de Ensino - Universidade Federal de Santa Catarina. Grupo CASULO: Pesquisa e Educação em Ciências e Biologia. E-mail: adriana.mohr.ufsc@gmail.com 


\section{SCIENCE TEXTBOOKS SELECTION AND USE: RESEARCH ON FLORIANÓPOLIS'} MUNICIPAL PUBLIC SCHOOLS

ABSTRACT: In this article we describe an investigation of some aspects related to the selection and use of science textbooks by school teachers in the municipality of Florianópolis, Santa Catarina, Brazil. We investigated the academic background and the teachers' beliefs about science textbooks, through semi-structured interviews with eight science teachers. This research is classified as a qualitative one and our results show that the science teachers are the ones responsible for the textbooks selection in the municipal schools in Florianópolis, and their choices are based upon the Directives of the Secretary of Education of the municipality and their school's pedagogic project. They agree that the whole process is satisfactory.

Keywords: Textbook. Science teaching. Teachers. Elementary School. 


\section{INTRODUÇÃO}

De forma geral, as pesquisas com livros didáticos (LD) de Ciências são recentes na literatura das áreas de Educação e Ensino, tendo início em quantidade considerável a partir da segunda metade do século XX. Choppin (2004) já afirmava que cerca de $75 \%$ das pesquisas com LD ocorreram há menos de 20 anos. Um estudo pioneiro sobre o estado da arte do LD no Brasil já apontava a história recente da pesquisa com esse objeto:

Como nos havíamos proposto estudar o livro didático, focalizando os estudos dos últimos quinze a vinte anos, os estudos feitos realizados nas décadas de 50 e 60 cairiam fora da nossa análise. A decisão de incluir alguns deles neste debate decorre do fato de que eles são efetivamente pioneiros, traçando rumos e fixando critérios. (FREITAG; MOTTA; COSTA, 1987, p. 49, grifo nosso)

Embora a partir desse período haja grande expansão no número de investigações sobre o conteúdo dos LD, Carneiro, Santos e Mól (2005) ainda afirmavam que eram poucos os estudos sobre o LD e seu cotidiano na sala de aula ou sobre as concepções dos professores e dos alunos sobre seu uso. A mesma lacuna foi constatada mais recentemente por Zambon (2012). O enfoque das pesquisas com o LD de Ciências até os dias atuais tem sido, quase sempre, outra temática:

\footnotetext{
Embora um número crescente de pesquisas e ações governamentais [...] tenha o livro didático (LD) como foco, observa-se, de forma geral, que estas pouco problematizam aspectos relacionados ao seu uso por professores e alunos no ambiente escolar nem as práticas de leitura a ele associadas. Em particular, é ausente a discussão das relações que o professor, mediador por excelência das interações entre livro-aluno-conhecimento, estabelece com este material. (CASSAB; MARTINS, 2008, p. 2)
}

De forma geral e concordando com as autoras, notamos que os estudos relativos ao LD que investigam seu uso pedagógico por professores da Educação Básica (EB) enquanto um instrumento são relativamente recentes, datando das últimas duas décadas. A pesquisa com esses materiais assumiu outras dimensões nesse período. Fernandes (2004, p. 533) afirma que estas "têm diversificado temas e documentos, dando conta tanto de sua concepção, produção, difusão e uso, quanto de suas relações com as políticas públicas, os currículos escolares e a indústria editorial".

Ferreira e Selles (2003), Choppin (2004) e Carneiro, Santos e Mól (2005) afirmavam que a maioria dos trabalhos e produções observados em suas pesquisas tratava da análise de conteúdos dos LDs de Ciências. Tais pesquisas tiveram muita importância dentro do contexto histórico no qual ocorreram. A denúncia por parte desses trabalhos de pesquisadores da área da Educação em relação à baixa qualidade dos LDs adquiridos pelo Governo Federal criou pressão sobre o poder público, que teve de estabelecer as comissões que avaliavam periodicamente a qualidade, o projeto gráfico e a proposta pedagógica das coleções inscritas no Programa Nacional do Livro Didático (PNLD) (BIZZO, 1996). 
Uma vez iniciadas as avaliações periódicas pelas equipes que elaboram o Guia de Livros Didáticos (GLD) pelo Ministério da Educação (MEC), notou-se uma sensível melhora das coleções distribuídas pelo PNLD, elevando-se o padrão de qualidade dos LDs no Brasil de uma maneira geral (BIZZO, 2000; EL-HANI; ROQUE; ROCHA, 2011). Em meados da década de 2000, as pesquisas que investigavam os processos pedagógicos e culturais, como o uso do LD, começaram a aumentar (TOLENTINO-NETO, 2003; BAGANHA, 2010; GUIMARÃES, 2011; SGNAULIN, 2012; ZAMBON, 2012).

A revisão bibliográfica desta investigação mostra que a produção brasileira sobre o LD atualmente vem crescendo em grande volume. Muitas dessas pesquisas relacionadas no último paragráfo e realizadas recentemente serão mencionadas e, às vezes, terão seus resultados comparados com aqueles obtidos no presente estudo. As constribuições e os dados desses autores nos ajudam a entender o contexto da realidade com a qual trabalhamos nesta investigação.

A seleção e a utilização do LD na escola, no âmbito do PNLD, tornaramse nosso objeto de pesquisa, uma vez que podemos observar (no campo e a partir de textos de outros pesquisadores) o quanto a articulação entre o trabalho dos docentes das escolas de EB, a estrutura desses estabelecimentos e a forma de funcionamento do PNLD apresentam desdobramentos pedagógicos. Esses reflexos podem ser observados através da forma pela qual os professores da EB selecionam, avaliam e usam os LDs de Ciências com seus alunos em sala de aula.

Dessa forma, a seleção e o uso do LD em algumas unidades escolares através das atividades dos professores de Ciências com os quais trabalhamos constituem nosso problema de pesquisa. Assim, fazemos alguns questionamentos a respeito da forma com que os livros são selecionados nas escolas, se há livros para todos os alunos, como os docentes participantes desse estudo selecionam as coleções, qual é o uso que os professores fazem do LD e, por último, qual a opinião dos docentes a respeito da qualidade e da diversidade das obras disponíveis para escolha.

Julgamos que analisar a seleção de LD na sistemática do PNLD por professores de Ciências é importante, uma vez que

A seleção dos livros didáticos para o Ensino de Ciências constitui uma responsabilidade de natureza social e política. Nesse processo os professores estão ou não valorizando o dinheiro do salário-educação, imposto relativo à compra de livros pelo MEC, estão tomando decisões que podem comprometer a educação das crianças. (NUÑEZ et al., 2001, p. 3)

Consideramos que esse fator justifica e embasa as razões para a condição de nossa pesquisa. Assim, o objetivo desta investigação é analisar a escolha e o uso de LD por professores de Ciências no âmbito do PNLD na rede de educação municipal de Florianópolis, Santa Catarina. 


\section{PROCEDIMENTOS E MÉTODOS DA INVESTIGAC̣ÃO}

A delimitação do campo de estudo ocorre em torno de professores de Ciências e suas posturas em relação ao LD, nosso objeto do estudo. Dessa forma, consideramos que esta investigação possui natureza qualitativa, uma vez que pretende identificar e analisar percepções, atitudes e significados (MINAYO; DESLANDES; GOMES, 2011) atribuídos por professores ao seu material didático e às suas formas de trabalho com ele.

Os sujeitos participantes são professores da disciplina de Ciências da rede municipal de ensino do município de Florianópolis, SC. A forma para se investigar a natureza do tema proposto foi a realização de entrevistas semiestruturadas com professores. Minayo, Deslande e Gomes (2011) afirmam que esse instrumento de coleta de dados fornece ao entrevistado a possibilidade de discorrer sobre o tema abordado sem se restringir à indagação inicialmente formulada pelos pesquisadores.

A rede municipal de Florianópolis possuía, no momento da investigação, 28 professores efetivos em atividade e um total de 26 escolas que possuíam os quatro anos finais do Ensino Fundamental. Os critérios de seleção dos sujeitos para entrevista foram (1) ser professor efetivo da rede em atividade, (2) atuar em escola localizada em uma das quatro grandes regiões geográficas do município ${ }^{1}$ e (3) aceitar participar da investigação. Foram entrevistados oito professores do componente curricular Ciências que atuavam em sete escolas de diferentes regiões geográficas do município. Os dados coletados nas oito entrevistas foram consideradas suficientes, de acordo com o critério de saturação (MINAYO, 2008). Segundo essa autora, "por critério de saturação se entende o conhecimento formado pelo pesquisador, no campo, de que conseguiu compreender a lógica interna do grupo ou da coletividade em estudo" (MINAYO, 2008, p. 197-198).

As entrevistas ocorreram no primeiro semestre do ano de 2012 nas escolas de EB de cada professor e duraram entre 15 e 40 minutos (média de 25 minutos), sendo audiogravadas e, em seguida, transcritas integralmente de acordo com as orientações de Carvalho (2006). Essa autora sugere, por exemplo, o uso de letras maiúsculas para trechos de ênfase na fala dos entrevistados, dois parênteses para indicar comentários do entrevistador, a fim de garantir melhor compreensão do texto, reticências para indicar interrupções na fala do sujeito participante de pesquisa. Essa autora também recomenda corrigir alguns vícios de linguagem, o que foi feito, mas tentamos preservar certa coloquialidade nas transcrições, características da maneira de falar e do sotaque dos florianopolitanos. As entrevistas foram realizadas após a apresentação de um Termo de Consentimento Livre e Esclarecido a cada professor entrevistado e a coleta da respectiva assinatura com ciência e aceite de participação, o que foi obtido de todos os professores que foram participantes deste estudo.

As entrevistas foram desenvolvidas a partir de um roteiro composto por quatro blocos, que versavam sobre os seguintes aspectos: (I) formação do professor para a escolha do livro, (II) processo de escolha do material, (III) aspectos relativos a quantidade e qualidade e (IV) uso do livro pelos sujeitos de pesquisa. A análise das transcrições foi efetuada destacando-se aspectos significativos e importantes das falas dos professores que permitissem identificar e compreender a percepção 
e a atividade dos docentes no que diz respeito aos quatro aspectos mencionados e que possibilitam responder à pergunta que norteou a investigação: como os professores de Ciências da rede municipal de Florianópolis selecionam e utilizam o LD em suas aulas?

Para preservar o anonimato dos sujeitos, os professores participantes dessa pesquisa foram identificados como PE-N². Os resultados são apresentados a partir de cada um desses quatro aspectos.

\section{RESULTADOS E ANÁLISE}

A análise dos resultados foi feita a partir dos quatro aspectos (I a IV) acima mencionados e é apresentada nos itens que seguem.

\section{Formação do professor para escolha do livro didático}

Com relação à formação inicial, todos os docentes entrevistados possuem Ensino Superior concluído e alguns deles cursaram pós-graduações (cinco professores são especialistas e um é mestre). Os professores têm entre oito e 30 anos de atuação no magistério, afirmam já ter participado de vários processos de seleções de LD e dizem que conhecem bem o processo de escolha pelas escolas.

Em relação à participação em cursos, palestras ou formações sobre análise de LD, seis docentes afirmam já ter participado de cursos promovidos pela Secretaria Municipal de Educação ou ter tido contato com o tema durante seu período de pós-graduação. Esses professores consideram tais momentos de formação como muito importantes para a escolha dos livros:

PE-7: Sim, a gente, na formação da prefeitura - ela nos oferece - todos os anos que tem escolba de livro a gente tem essa formação, para conhecer os livros... até alguns autores ((de livros)) vem nos colégios... a gente tem sim...

$\mathrm{Na}$ rede municipal de Florianópolis os professores frequentam semanalmente reuniões pedagógicas por áreas de conhecimento. Os professores entrevistados valorizam estes momentos de planejamento e encontro dos docentes de Ciências. Em tais reuniões, à época da escolha dos LD, os professores discutem os títulos presentes no GLD editado pelo MEC (BRASIL, 2010) para selecionar os livros que serão solicitados. Os docentes afirmam que este momento é então utilizado para discussão, conhecimento mais detalhado de cada obra, estabelecimento de critérios de análise e seleção dos LD, de acordo com os eixos temáticos presentes na Proposta Curricular do município.

Três dos professores entrevistados dizem conhecer ou ter tido contato com o GLD e consideram importante este documento, enquanto três outros docentes não conhecem o GLD e consideram mais relevante a reunião específica do grupo de professores de Ciências, mencionada anteriormente, para análise e discussão dos LD. Existem ainda dois docentes que conhecem o GLD, mas não o utilizam para selecionar os LD, pois consideram importante apenas o momento da análise e da discussão das obras dentro do grupo de professores da rede: 
Seleção e uso do livro didático: um estudo com Professores de Ciências na rede de Ensino Municipal de Florianópolis

PE-7: [...] mas ai aquilo ali a gente dá uma lida e tal... mas o que VALE mesmo é o que a gente discute no nosso grupo ((de professores de Ciências do município))...

PE-8: Não, eu acho que eu nunca cheguei a pegar o Guia assim para ler, sabe... é sempre o próprio livro... eles ((as editoras)) mandam os livros, a gente se reúne...

Podemos inferir, com os excertos acima, que, ao contrário dos dados apontados por Maffia e colaboradores (2002) e Zambon e colaboradores (2011), a maioria dos professores entrevistados em nosso estudo conhecia o GLD, embora nem todos julgassem esse material integrante do PNLD importante no processo de escolha do LD.

Essa situação corrobora aquela encontrada por Sgnaulin (2012), realizada na rede pública de Campo Grande (MS): os professores experientes conhecem o GLD, mas, para a escolha do LD, utilizam sua própria experiência profissional. Notamos, especialmente entre os docentes com mais tempo de atividade, que estes consideram que conhecer o LD para realizar a escolha faz parte de seus saberes docentes e profissionais, mesmo com o reconhecimento de que não existe tempo específico para a atividade de escolha das coleções:

PE-1: [...] não há momento específico dentro do meu tempo de trabalho... eu tenho todo o ano anterior para conhecer e ler as obras que eu vou selecionar para o ano seguinte, né... eu acho o tempo adequado... esse é um processo que é parte do meu trabalho...

PE-2: [...] não existe um momento especifico, né... mas o professor tem três anos para ficar com o material que ele vai acabar trabalhando... então é dever dele conbecer bem esse LD...

Sgnaulin (2012) ainda afirma que o professor em período inicial do exercício docente vai aprendendo a escolher e utilizar o LD ao longo de suas atividades profissionais, pois os aspectos relativos ao LD são pouco abordados na formação inicial. Nossos resultados reforçam aqueles encontrados pela autora: o professor aprende a escolher o LD ao longo de sua vivência no magistério. Observamos, assim como no estudo de Tolentino-Neto (2003), realizado com professores de Ciências de anos iniciais de cinco cidades em distintas regiões geográficas do Brasil, que, quanto maior o tempo de atividade do docente entrevistado, mais capaz ele se considera para fazer a seleção do LD com que trabalha.

Dentre os professores entrevistados, dois docentes estão satisfeitos com o tempo disponível para discussão e escolha do LD, mas seis deles consideram que o período para essa atividade deveria ser ampliado:

PE-5: [...] não é o mais adequado, mas é o que a gente teve disponivel, né... ((professor ri))... foi o que deu para fazer...

PE-6: [...] na verdade a gente tá acostumado a trabalhar assim... final de semana, à noite... então a gente acaba achando meio normal, mas não é... não DEVERIA ser, né... abn ... poderia ter MAIS tempo, mas ai tu dependes... o guia do MEC até vem com bastante antecedência, mas os LIVROS não vem... as coleções não vem para a escola... [...] 
Em relação à formação específica para a escolha do LD de Ciências, os professores entrevistados mencionam apenas palestras com editoras e autores de LD:

PE2: [...] o que acontece é assim... os AUTORES dos LD, eles acabam vindo divulgar a sua obra e dai existe PALESTRA para os professores e a gente participa de algumas dessas palestras... onde ele apresenta sua obra, tenta vender seu peixe na verdade, né...

PE3: Nós tivemos alguma coisa aí com a prefeitura... com alguns autores ((de $L D))$ até... vieram autores apresentar as coleções e tudo... [...]

PE7: [...] todos os anos que tem escolba de livro a gente tem essa formação, pra conbecer os livros... até alguns autores ((de $L D))$ vem nos colégios... [...]

Observamos, no grupo entrevistado, problemas no processo de escolha do LD originados no tempo ou no espaço disponível para essa atividade: dadas as condições de trabalho, essa e outras tarefas docentes são feitas além da jornada de trabalho regulamentar do professor. Além disso, notamos que as práticas e os conhecimentos relacionados ao LD de Ciências, seja a escolha ou o próprio uso, são experiências pouco abordadas nas formações inicial e continuada dos docentes, um problema que potencialmente repercute nas práticas dos professores com esse material ao longo de sua vida profissional. Isso é lastimável, uma vez que não consideramos a escolha do LD como uma tarefa simples ou fácil na atividade docente.

Nardi (1999) já sugeria que a formação inicial dos licenciados e a formação continuada dos docentes falhava em alguns aspectos, principalmente quando não existem oportunidades nos cursos para se produzir, discutir e avaliar materiais didáticos pelos docentes. Segundo o autor, se os licenciados produzissem os próprios materiais didáticos durante o período da formação inicial, esses futuros docentes estariam mais preparados para selecionar e trabalhar com esses materiais dentro das escolas, no momento de suas práticas profissionais.

Já Tardif (2012), discutindo as mudanças necessárias na formação docente, sustenta que, geralmente, as disciplinas pedagógicas dos cursos de Licenciatura se apresentam fechadas em si mesmas, sem sentido ou conexão. $\mathrm{Na}$ visão do autor, o currículo e as disciplinas dos cursos, organizados dessa forma, pouco ajudam a bem formar o profissional professor, pois a reflexão sobre o ensino e a aprendizagem perde espaço para os conteúdos teóricos na grade curricular das Licenciaturas. Além disso, o docente, apesar de ser um formador, tem pouco ou nenhum espaço para pensar e refletir sobre a própria formação dentro de seu campo de atuação (TARDIF, 2012).

Para Carvalho e Gil-Pérez (2011), a formação dos professores deveria ser permeada por situações como experiências de tratamento de novos domínios em função de mudanças curriculares, avanços científicos e questões propostas pelos alunos. Interpretamos essa afirmação como a pertinência para os licenciandos experienciarem continuamente a prática docente, a análise de material didático aí incluída, para conferir significado à sua formação inicial. 


\section{Escolha do livro didático na escola}

Os professores de Ciências entrevistados afirmam que a seleção do LD é de responsabilidade dos docentes em atividade em todas as unidades escolares e declararam não sofrer qualquer constrangimento com indicações ou orientações externas ao grupo de docentes da área de Ciências, como a direção e a coordenação das escolas. Contudo, sinalizam que editoras enviam autores para ministrar palestras e cursos de formação continuada, além de exemplares de LDs às escolas públicas:

PE-3: Cada editora traz a sua... a sua coleção... teve uma... acho que na última vez, que nós formamos grupos... cada grupo analisou uma ou duas coleções... apresenta essa análise para o grande grupo ((de professores da rede))... e dai a gente decide... mas você tem autonomia para decidir o livro para a tua unidade...

PE-4: primeiro a gente faz uma escolha interna ((dentro da unidade escolar)) e depois, como tem o grupo de Ciências ((da rede municipal)), normalmente a gente faz a escolha em grupo, né... [...] a gente já conbece algumas obras, alguns autores... e ai a gente normalmente se manifesta...

Os professores afirmam proceder à seleção do LD em função da proposta curricular do município:

PE-6: [...] eu sempre olho dentro da proposta curricular da rede ((municipal)), né... porque a rede tem uma proposta curricular, então a gente vê os ((livros)) que estão dentro desta proposta curricular... [...]

PE-8: Olha, quando dá tempo, os próprios professores ((de Ciências)) se reínem e aí analisam os livros... $e$ ai, de acordo com a proposta do município, de acordo com a grade curricular que a gente tem... a gente seleciona os ((livros)) que chegam mais próximos, né, à nossa proposta de trabalbo...

Resultados semelhantes sobre a escolha dos LDs foram encontrados nos estudos de Tolentino-Neto (2003) e Sgnaulin (2012). Outro fator importante para a seleção mencionado pelos professores foi a questão da adequação do LD ao Projeto Político-Pedagógico (PPP) das escolas:

PE-3: [..] porque a gente sempre tenta... sem às vezes até pensar no projeto politico-pedagógico, a gente já pensa numa coleção que esteja dentro do... do pensamento da escola, vamos dizer assim... das diretrizes da escola...

PE-8: [...] dentro dos PPP a gente tem a proposta curricular por áreas e também a proposta da escola como um todo, né... quais são os aspectos mais importantes para a gente estar trabalhando na escola... $e$ ai eu acho que a seleção ((do LD)) leva em consideração tudo isso... a proposta que a escola se propõe a desenvolver enquanto formadora e educadora, né... a gente busca tentar selecionar isso, né...

Os docentes sentem-se livres para realizar suas escolhas dento das obras disponíveis no GLD, mas consideram que essa lista já funciona como uma préseleção do MEC: 
PE-4: [...] não adianta a gente chegar no grupo e dizer que tem uma obra ótima no mercado, né... saiu assim e todo mundo quer adotar... a prefeitura não vai bancar isso... porque como esses livros vem do governo federal, né... eles ((os professores de Ciências do município)) não tem essa ingerência de propor uma outra obra que não faz.parte daquelas ((presentes no GLD))...

Os professores ouvidos também consideram a discussão realizada no grande grupo composto por todos os professores de Ciências do município muito importante para a escolha desses materiais:

PE-7: Primeiro que a escolha que foi feita... é produto de uma discussão, não de uma imposição... o nome dos livros já é uma imposição, que alguns ai o comitê ((professor se refere ao comitê de avaliadores que compõem a equipe que formula o GLD)) escolheu e já vem imposto... pra você ganhar o livro GRÁTIS, pra você ter o livro pro aluno GRÁTIS, tá dentro daquele... daquela relação ((professor se refere ao GLD)) mas quando essa relação chega pra nós, pra mim o importante é que tenha essa discussão porque nada melhor que você conversar com seus pares...

Dentre os 11 títulos integrantes do GLD de 2011, o grupo de professores de Ciências da rede municipal de ensino definiu três coleções como elegíveis para escolha na disciplina de Ciências nas escolas da rede municipal. Esse limite para escolha de títulos é estabelecido pelo grupo nas reuniões da área e objetiva que haja poucos títulos diferentes em uso na rede:

PE-2: ...não é BEM uma decisão da escola... é uma decisão do grupo ((dos professores de Ciências do município)) e a escola, ela acaba tendo que optar por uma das três coleções...

PE-5: [...] senta todo mundo, ai a gente escolbe qual que é o melhor ((livro))... qual é a primeira opção, a segunda opção... assim, né, não é obrigatório tu fechares com a rede... tipo, se a rede escolbeu uma primeira e uma segunda opção e en quero uma terceira, en posso ficar com essa terceira... aí eu converso com o outro professor de Ciências, assim...

Segundo os docentes, há duas razões principais para esse procedimento: a possibilidade de permuta de LD entre as unidades escolares (motivos alegados por PE-2, PE-3 e PE-6), quando as obras selecionadas são semelhantes, e a mobilidade dos alunos dentro da rede municipal (razão alegada por PE-5). Tal situação de migração de alunos entre diferentes escolas em uma mesma rede foi, também, encontrada na investigação de Tolentino-Neto (2003), quando este analisou o tema no município de Palmas, Tocantins.

Tais aspectos e condicionantes relativos à seleção de LD levam-nos a refletir sobre esse processo: ao mesmo tempo que requer uma formação específica, é altamente formador, uma vez que confronta o professor com condicionantes de macro e micropolítica educacional e demanda do docente decisões que impactarão a sua prática cotidiana. Nessas condições, como afirmam Baganha, Gonzalez e Boal (2011, p. 8), “'Tanto o livro quanto o Programa constituem-se ferramentas importantes para o processo ensino-aprendizagem e podem ser melhorados com a participação efetiva dos professores". Considerando o processo verificado na rede municipal de Florianópolis exposto anteriormente, ressaltamos a importância 
não só da manutenção, mas da expansão dos momentos de formação continuada já existentes e mencionados pelo grupo de professores participantes da pesquisa.

\section{Quantidade e qualidade do livro didático}

Dois docentes assinalaram que faltam livros na escola, pois o número de alunos matriculados no ano de uso do livro é superior àquele do ano em que ocorre a escolha. Verificamos relatos de permuta de LD entre escolas ou demanda da escola para obter mais exemplares do LD na reserva técnica da Secretaria de Educação para suprir esse problema:

PE-1: [...] de vez em quando, porque não bá uma compatibilidade do número, né... não tem ainda exatamente o número de matrículas... tu tens que te basear no número do ano anterior para fazer o pedido ((dos livros)), então às vežes há um probleminha assim... uma turma fica com outros livros... mas não chega a comprometer, né... de uma maneira geral, todo mundo tem o livro...

PE-7: [...] eu comecei a trabalhar aqui em 2001, 2002... tinha 580 alunos, hoje tem 1.080... né, tem 1.080, então no ano anterior ele vai ter sempre menos livro que no ano que está por vir... mas eles ((a Secretaria de Educação)) mandam ((os livros)) por cadastro do ano anterior, eles não atualizam... e ai os bibliotecários fazem o POSSÍV EL pra conseguir mais livros, né... eles vão, eles mandam e-mail para todas as escolas para ver se tem reserva técnica, para ficar trocando os livros... [...]

O estudo de Sgnaulin (2012) mostrou a mesma situação de subestimativa de compra e distribuição de LD em Campo Grande. Nesse aspecto e pela recorrência do problema em distintas regiões, faz-se necessário um aperfeiçoamento do PNLD no sentido de prover material necessário para todos os alunos.

Os docentes entrevistados foram unânimes ao afirmar que o PNLD tem respeitado suas escolhas, enviando para as escolas sempre o livro solicitado em primeira opção pelos professores, com exceção de um caso, justificado pela perda de prazo para a realização do pedido:

PE-5: [... teve um problema que teve a greve do correio ((professor ri)), não sei se tu lembras... e o livro que a gente escolheu, não teve tempo hábil de chegar onde tinha que chegar a solicitação e veio o livro que o MEC mandou... não foi o que a gente tinha pedido... mas a maioria das vezes sim...

A maioria dos entrevistados julga possuir boas opções de LD para a escolha. Os resultados de Martins, Sales e Souza (2009) já apontavam que os professores vinham valorizando novos aspectos ao escolherem os LDs. Assim, pensamos que o incremento nas investigações e o aumento da importância e das discussões sobre o processo de escolha e debate em torno do LD, além da abordagem desse tema na formação inicial, podem explicar a atenção e a valorização crescente desse importante elemento didático, bem como de sua seleção. Nesse sentido, concordamos com Nuñez e colaboradores (2001), que afirmam que o trabalho dos professores é complementar às ações do MEC, no âmbito do PNLD.

No que diz respeito a critérios considerados como indicadores de um bom LD, os professores entrevistados elencaram alguns aspectos, que 
apresentamos e discutimos a seguir. Os principais itens mencionados foram a forma como o LD apresenta a sequência dos conteúdos, a mobilização dos conhecimentos (relação entre o conhecimento prévio do aluno e o saber científico apresentado nos livros), a potencialidade de o LD despertar a curiosidade do estudante e se o LD apresenta os conteúdos de forma atualizada e correta. Além desses fatores, também há menção a formatação, diagramação e escolha dos textos presentes, esquemas, gráficos, tabelas e a um livro que faça o aluno refletir sobre os conhecimentos e atenda à proposta curricular do município de Florianópolis.

Em relação aos elementos que os professores consideram mais importantes na escolha de um LD, estes são: texto (verbal e imagens), formatação, qualidade e tipo das imagens (mencionados por PE-1), mobilização de conhecimentos prévios, sequência dos conteúdos, contextualização dos conteúdos abordados (citados por PE-2), adequação dos conteúdos do livro ao plano de ensino e à proposta curricular de Ciências para o município (lembrados por PE-3 e PE-8), presença de mapas conceituais e gêneros textuais diferentes (apontado por PE-4) e correção conceitual (resposta do professor PE-6). Os professores também julgam importante que o LD selecionado proponha reflexões ao estudante, não apenas memorização ou cópia de conteúdos. Todos esses fatores são elementos importantes para os professores entrevistados não só no momento da escolha, mas também para a análise e a discussão em grupo dos LDs.

A visão de natureza integrante do ensino de Ciências, a atualização dos conteúdos e a possibilidade do pensar e refletir sobre os conhecimentos científicos também preocupam dois dos professores na hora da escolha dos LDs:

PE-2: [...] o tipo de atividade... se são atividades de mera repetição dai eu não... eu abomino assim... então atividades que façam o aluno PENSAR a respeito do conbecimento cientifico, não só dar uma resposta única ali pra aquele conteúdo...

PE-6: PRA MIM é que tem conteúdo, BOM conteúdo... conteúdo ATUALIZADO, conteúdo CORRETO também... [...] então o livro é SEMPRE o texto que o aluno tem em casa, que eu posso cobrar dele porque eu sei que ele tem aquele texto ali... então dentro daquilo ali eu posso cobrar do aluno [...]

Em nossos resultados, verificamos, de forma geral, que os professores entrevistados valorizam aspectos importantes, escolhem e usam os LDs de forma a minimizar o efeito notado por Quesado (2012) quando afirma que esse material muitas vezes contribui para uma visão da Ciência como atividade dogmática, positivista, puramente empirista e reduzida a uma sucessão de acertos ao longo de sua trajetória temporal.

No entanto, a ênfase em uma correção conceitual absoluta necessita ser questionada, tal como fazem Cassab e Martins (2008, p. 7):

[...] A discussão do critério correção conceitual é emblemática neste sentido. Três fatores poderiam justificar sua adoção no processo de seleção do material didático: a compreensão do aluno como destituído de crítica e sensível aos possíveis erros veiculados no $\mathrm{LD}$, a percepção da missão do livro associada à veiculação de saberes considerados 
cientificamente corretos e a questão da defasagem entre a produção do conhecimento científico e sua recontextualização no material educativo [...].

\section{Dentre os elementos dos LDs que mais chamam a atenção dos} docentes temos atividades propostas pelos autores das obras (lembrados por PE-2 e PE-3), presença de relações com outros campos de conhecimento e disciplinas escolares (mencionados por PE-1), contextualização dos conteúdos (apontados por PE-4 e PE-7), estruturação, diagramação, formatação do LD (descritos por PE-7 e PE-8), atualização e correção conceitual da obra (lembrado por PE-5). Além dos anteriores, as imagens foram mencionadas por todos os docentes entrevistados.

Esses dados parecem ir ao encontro dos estudos de Cassab e Martins (2008), que afirmam que itens como linguagem, conteúdo, correção conceitual, contextualização dos conteúdos e a própria formatação dos LDs são aspectos muito importantes para seleção e uso pelos professores de Ciências. Essas autoras ainda afirmam que os professores tendem a considerar, em suas escolhas, a realidade dos alunos com os quais trabalham: "[...] Assim, percebemos que, na escolha do livro didático, caminham de mãos dadas considerações a respeito do público que o livro se destina e preocupações propriamente relativas ao ensino de Ciências" (CASSAB; MARTINS, 2008, p. 6).

Por fim, como todos os professores entrevistados nesta investigação mencionaram as imagens como aspecto importante para a seleção de LD, julgamos que é importante desenvolver mais processos formativos sobre o papel e a significação da imagem no material didático, pois, como afirmam Cassab e Martins (2008, p. 16):

[...] Ao confrontarmos as significações dos professores a respeito dos aspectos visuais na seleção do livro didático, com esta compreensão mais estendida do papel da imagem, há algumas ausências e também a construção de outros significados. No discurso dos professores que participaram desta investigação, os aspectos visuais do LD são pensados, em geral, em relação a dois aspectos: (i) imagem de aluno mau leitor, desinteressado e permeável a apelos visuais e (ii) imagens do livro como alternativas às condições logísticas da escola e a dificuldade de promoção de vivências aos alunos. (CASSAB; MARTINS, 2008, p. 16)

Os docentes entrevistados nessa investigação sabem da importância e dão valor à seleção do material com o qual irão trabalhar em sala de aula. Os LDs, na visão desses professores, vêm melhorando nos últimos anos em função do desenvolvimento do programa de avaliação dos LDs, trabalho iniciado em meados da década de 1990.

\section{Utilização do livro didático pelo docente}

Os dados obtidos através das entrevistas permitem concluir que o LD é utilizado pelos professores no momento do planejamento das aulas e como fonte de consulta, exercícios e leituras pelos alunos. Os professores afirmam que não é sempre que utilizam os LDs em suas aulas, pois, em muitos casos, não há livros 
para todos os alunos. Dois professores relataram utilizar outros recursos, como vídeos, mapas conceituais, esquemas resumidos e saídas de estudo em ambientes externos das escolas.

Tais resultados também foram encontrados por Sgnaulin (2012). A concordância dos resultados desses dois estudos aponta para outra tendência de uso do LD: ele continua muito importante, mas não é mais a única ferramenta utilizada no ensino e na aprendizagem dos conteúdos científicos em sala de aula.

Quando se referem à forma de trabalho e ao uso do LD em suas aulas, os professores apontam alguns aspectos da utilização desse material, como leituras de textos, realização de exercícios e pesquisas pelos seus estudantes:

PE-1: ...trabalhando os textos... fundamentalmente trabalhar os textos... e quando eu percebo que o livro tem uma boa sequência didática, atividades que vão complementando esse trabalho com o texto... eu pego, sem nenhum constrangimento, essa sequência didática...

PE-3: Eu indico bastante exercicio do LD... tem esta parte de imagens que eu te falei, que agora esse ano eu comecei a trabalhar com os sextos anos... parece que eles sentem mais necessidade de ter o livro ali... você vai chegando numa oitava, ali já não precisa tanto assim... mas eu não tenho oportunidade de trabalhar todo dia com o LD, como te falei... mas eu tento trabalhar NO MÍNIMO na minha aula faixa que eu tenho na semana... com todas as turmas eu tenho pelo menos uma aula faixa... então nesse dia eu tento trabalhar com o livro...

PE-5: Eu utilizo bem para pesquisa mesmo ((professor ri))... ah, eu... tipo, agora eu estava utilizando o livro... en falo um pouquinho de um assunto, deixo eles ((os alunos)) meio curiosos... e dai eu faço eles irem lá e pesquisar... ou então eu vejo se tem algum texto... [...]

Os professores participantes do presente estudo demonstram não depender do uso do LD, mas consideram-no um importante material para consulta dos alunos, uma vez que afirmam que, muitas vezes, talvez ele seja a única fonte de leitura para informação e conhecimento do estudante e de sua família:

PE-2: [...] o nosso aluno, eu tenho bem claro que a maioria dos nossos alunos é o único material que ele tem disponivel de leitura, na... principalmente na sua casa... então eu acho que, de certa forma, é um material que se tem que usar até tendo em vista esse contexto, né... de ter carência mesmo de material de leitura em casa $[. .$.

PE-6: [...] mas então o livro é sempre um APOIO, tá... eles leem em casa ou eu dou uma atividade dirigida em que eles tem que pesquisar no livro, tá...

Os docentes entrevistados conhecem o potencial de alcance dessa ferramenta e ressaltam que não podem planejar e desenvolver suas aulas de forma totalmente independente desses livros. Alguns professores até dizem conseguir desenvolver suas aulas sem o LD, embora considerem mais difícil trabalhar dessa forma, tal como verificamos nos dois excertos a seguir: 
PE-1: Conseguiria, mas eu não gostaria... porque eu acho ele ((o LD)) uma ferramenta bem importante, como eu te falei... pela quantidade de texto, pela sequência didática, pelo aquilo que ele pode proporcionar para o aluno em casa... porque o aluno... o livro é dele, ele leva pra casa... nós estamos numa escola pública... muitas vežes, dependendo do letramento da família, são os livros didáticos materiais desse tipo... para família... e não mais que isso, então eu acho bem importante ter um livro, entender como é esse livro, poder manipular, poder ir lá paro fim do livro...

PE-7: Porque paro aluno é importante ele ter acesso a essa imagem que está aqui, entendeu... para o aluno é importante ele ter, ele ver o que é que a fala está no livro... dar importância ao escrito e publicado, entendeu... e as imagens... você não pode falar, às vezes você tem que ver, né... então eu acho que paro aluno seria muito difícil... porque para a gente ((os professores)), como a gente tem a nossa grade já... nós já temos isso estabelecidos nos nossos cursos, né... currículo e tal... a gente já sabe o que é que tem que dar ((conteúdo)) por bimestre, né... já tá uma coisa mais especificada... eu PODERIA dar sem livro, mas eu acho que ia ser pobre, entendeu... ai ia ser um argumento mais empobrecido, aí você vai ter que usar outros apetrechos, né... muito vídeo, muito banner... muito... outro tipo de apoio, né... mas poderia... mas eu acho uma CONQUIST A o aluno TER o livro boje, de graça... eu acho uma conquista e não deve ser desprezada, deve ser bem escolbida...

Embora as entrevistas com os professores não tenham explorado especificamente o uso do livro tal como fez Delizoicov (1995), pensamos que as categorias elencadas por aquela autora se adequam aos resultados deste estudo. Assim, pensamos que cinco dos professores entrevistados neste estudo possuem um perfil que se aproxima de um professor do tipo 'em transição', pois

[...] Ainda que esse professor não utilize o livro didático como único recurso didático pedagógico e não faça do mesmo o direcionador das atividades, pressupõe-se que não realiza de forma satisfatória o "discurso da análise de texto", (GIROUX, 1988) uma vez que desvelou apenas parcialmente as idéias subjacentes no texto por ele examinado. (DELIZOICOV, 1995, p. 87)

E três professores possuem características de um professor do tipo 'transformador', aquele que consegue ter autonomia e definir o uso (crítico) que fará do LD (em vez de ser pautado por este):

Apesar dos alunos possuírem o livro didático, o professor não faz do mesmo o direcionador das atividades. O livro passa a figurar entre outros recursos selecionados e levados para a sala de aula pelo professor. (DELIZOICOV, 1995, p. 88)

À guisa de síntese das análises, podemos dizer que, de maneira geral, os professores entrevistados são cônscios e preocupados com os aspectos relacionados à seleção e ao uso dos LDs em sala de aula. Esses docentes mostraram, em suas falas, que estão inseridos e se consideram integrantes do processo do PNLD, uma vez que leem as obras didáticas, participam ativamente da seleção dos livros, discutem a qualidade dos volumes entre seus colegas de profissão e, finalmente, procedem à seleção dos LDs. No entanto, tanto alguns dos entrevistados, como os autores deste texto assinalamos que, com relação à participação dos docentes 
da Educação Básica no processo de avaliação dos livros e na elaboração do GLD, muito ainda há a melhorar: os professores da Educação Básica devem integrar em maior número as equipes avaliadoras, pois só assim o processo estará mais adequado e adaptado às necessidades de quem de fato utiliza o livro em seu trabalho cotidiano.

Quanto ao uso, os docentes entrevistados apoiam-se e servem-se dos livros, seja para planejamento, seja para atividades em sala de aula, mas não se sentem dependentes das obras escolhidas. As falas dos professores permitem, também, verificar o quanto o saber sobre o LD faz parte do saber docente e, como tal, aprimora-se ao longo da vida profissional e se beneficia de experiências vividas ao longo do seu trabalho docente com os colegas de profissão (TARDIF, 2012).

\section{CONSIDERAC̣ÕES FINAIS}

Após a análise das falas dos professores e considerando o objetivo da investigação descrita neste artigo, destacamos alguns aspectos da seleção e do uso do LD por alguns professores da rede municipal de Florianópolis, participantes desta pesquisa.

Um primeiro ponto que consideramos importante é que o grupo de professores de Ciências entrevistados é o responsável pela escolha do LD no município de Florianópolis. Embora alguns professores reconheçam que estejam limitados às obras presentes no GLD, o professor demonstra satisfação com seu poder de decisão sobre esse material. A forma como se dá a escolha - em conjunto e fruto do espaço permanente de encontros da equipe de Ciências - propicia discussões e troca de informações entre os pares para decidir sobre a melhor obra a se adotar em todas as escolas dentro do grupo de professores da disciplina.

Concordamos com Nardi (1999) quando este afirma que assumir a figura do professor como principal responsável pela seleção das obras didáticas é um bom caminho para que se melhore a qualidade do ensino. Destacamos, também, que as declarações dos professores nos permitem inferir a enorme importância pedagógica e curricular do espaço e do tempo semanal de encontro da equipe de professores. Especificamente, o estudo e a análise do LD pelo grupo dos professores de Ciências é, também, um fenômeno altamente formador do docente. Conforme afirmam Echeverría, Mello e Gauche (2010), o professor, quando conhece e avalia de fato o livro com que trabalha, também pode passar a dominar e entender o porquê dos conteúdos que ensina em sala de aula.

Quanto ao uso, verificamos que o grupo de professores entrevistados se apoia no LD, mas não tem nele a única fonte de recursos didáticos utilizados em sala de aula. Mais do que isso, nossos resultados permitem dizer que o grupo de professores tem uma postura crítica e bastante analítica do material disponível e selecionado. Assim, podemos afirmar que, com relação aos sujeitos envolvidos neste trabalho, o LD deixou de ser o elemento central do processo de ensino para constituir-se em um importante material de apoio.

Observamos, com esta investigação, que o professor tem se adaptado a uma nova forma e realidade de trabalho, em que todos os livros - não apenas 
os didáticos - saíram do centro das atenções dos estudantes e estão dando espaço a outras formas de comunicação e divulgação do conhecimento, como os meios eletrônicos e a internet, por exemplo. Assim, e de acordo com as falas dos professores entrevistados, parece-nos irreversível a constatação e a realidade de que o LD deixou de ser o único instrumento possível em aula e passou a ser mais um dentre os recursos didáticos.

Outras investigações que analisem a interação desses novos recursos presentes na sala de aula com o LD, tanto na atividade docente, quanto naquela dos alunos, serão de extremo interesse para a área de pesquisa em Educação em Ciências.

\section{AGRADECIMENTOS}

Os autores expressam seu agradecimento aos pareceristas que analisaram este texto, uma vez que suas sugestões e comentários permitiram aperfeiçoar sobremaneira a versão final do artigo.

\section{NOTAS}

\footnotetext{
${ }^{1}$ Após havermos entrevistado os quatro primeiros professores em cada uma dessas distintas regiões, buscamos contato em outras diferentes escolas, de forma que, com uma exceção, foram entrevistados dois professores atuantes em duas escolas de cada grande região geográfica do município.

${ }^{2}$ Onde PE corresponde a professor entrevistado e $\mathrm{N}$ é o número da realização da entrevista.

${ }^{3}$ GIROUX, H. Escola Crítica e Política Cultural. São Paulo: Ed.Cortez, 1988.
}

\section{REFERÊNCIAS}

BAGANHA, D. E. O papel e o uso do livro didático de Ciências nos anos finais do ensino fundamental. 2010. 121 f. Dissertação (Mestrado em Educação) - Setor de Educação, Universidade Federal do Paraná, Curitiba. 2010.

BAGANHA, D. E.; GONZALEZ, C. E. F.; BOAL, D. G. O livro didático de Biologia: a escolha de um recurso adequado à prática docente. In: ENCONTRO REGIONAL SUL DE ENSINO DE BIOLOGIA - EREBIO, 5.; ICASE, 4., 2011, Londrina - PR. Anais... Londrina: Desafios da Ciência entremeando culturas, 2011. CD-ROM.

BIZZO, N. A avaliação oficial de Materiais Didáticos de Ciências para o Ensino Fundamental no Brasil. In: ENCONTRO PERSPECTIVAS DO ENSINO DE BIOLOGIA - EPEB, 7., 2000, São Paulo. Anais... São Paulo, 2000. p. 54-58.

BIZZO, N. Graves erros de conceito em livros didáticos de Ciência. Ciência Hoje, Rio de Janeiro, v. 21, n. 121 , p. 26-35, 1996.

BRASIL. Ministério da Educação. Secretaria de Educação Básica. Guia de livros didáticos: PNLD 2011: Ciências. Brasília: Ministério da Educação, 2010. 
CARNEIRO, M. H. S.; SANTOS, W. L. P.; MÓL, G. S. Livro didático inovador e professores: uma tensão a ser vencida. Ensaio: Pesquisa em Educação em Ciências, Belo Horizonte, v. 7, .n. 2, p. 35 45, 2005.

CARVALHO, A. M. P. Uma metodologia de pesquisa para estudar os processos de ensino e aprendizagem em salas de aula. In: SANTOS, F. M. T.; GRECA, I. M. (Org.). A pesquisa em ensino de Ciências no Brasil e suas metodologias. Ijuí: Ed. Unijuí, 2006. v. 1, p. 13-48.

CARVALHO, A. M. P.; GIL-PÉREZ, D. Formação de professores de Ciências: Tendências e Inovações. 11. ed. São Paulo: Cortez Editora, 2011.

CASSAB, M.; MARTINS, I. Significações de professores de Ciências a respeito do livro didático. Ensaio: Pesquisa em Educação em Ciências, Belo Horizonte, v. 10, n. 1, p. 97-116, 2008.

CHOPPIN, A. História dos livros e das edições didáticas: sobre o estado da arte. Educação e Pesquisa, São Paulo, v. 30, n. 3, p. 549- 566, 2004.

DELIZOICOV, N. C. O professor de Ciências naturais e o livro didático (No Ensino de Programas de Saúde). 1995. 128 f. Dissertação (Mestrado em Educação) -Universidade Federal de Santa Catarina, Florianópolis. 1995.

ECHEVERRÍA, A. R.; MELLO, I. C.; GAUCHE, R. Livro didático: análise e utilização no ensino de química. In: SANTOS, W. L. P.; MALDANER, O. A. (Org.). Ensino de Química em Foco. Ijuí: Ed. Unijuí, 2010. p. 263-286.

EL-HANI, C. N.; ROQUE, N.; ROCHA, P. L. B. Livros Didáticos de Biologia do Ensino Médio: Resultados do PNLEM/2007. Educação em Revista (UFMG), Belo Horizonte, v. 27, n. 1, p. 211-240, 2011.

FERNANDES, A. T. C. Livros didáticos em dimensões materiais e simbólicas. Educação e Pesquisa, São Paulo, v. 30, n. 3, p. 531-545, 2004.

FERREIRA, M. S.; SELLES, S. E. A produção acadêmica brasileira sobre livros didáticos em Ciências: uma análise em periódicos nacionais. In: ENCONTRO NACIONAL DE PESQUISA EM EDUCAÇÃO EM CIÊNCIAS - ENPEC, 4., 2003, Bauru. Anais... Bauru, 2003. CD-ROM. FREITAG, B.; MOTTA, V. R.; COSTA, W. F. O estado da arte do livro didático no Brasil. Brasília: Instituto Nacional de Estudos e Pesquisas Educacionais (INEP), 1987.

GUIMARÃES, F. M. Como os professores de $6^{\circ}$ ao $9^{\circ}$ anos usam o livro didático de Ciências. 2011. 109 f. Dissertação (Mestrado em Educação) - Faculdade de Educação, Universidade Estadual de Campinas, Campinas. 2011.

MAFFIA, A. M. C.; et al. Livro didático de Ciências: o real e o idealizado em sua seleção. In: ENCONTRO PERSPECTIVAS DO ENSINO DE BIOLOGIA - EPEB, 8., 2002, São Paulo. Anais... São Paulo, 2002. CD-ROM.

MARTINS, E. F.; SALES, N. A. O.; SOUZA, C. A. O Estado, o mercado editorial e o professor no processo de seleção dos livros didáticos. Estudos em Avaliação Educacional, São Paulo, v. 20, p. 11-26, 2009.

MINAYO, M. C. S. O desafio do conhecimento: pesquisa qualitativa em saúde. 11. ed. São Paulo: Ed. Hucitec, 2008.

MINAYO, M. C. S.; DESLANDES, S. F.; GOMES, R. Pesquisa social: teoria, método e criatividade. 30. ed. Petrópolis: Vozes, 2011.

NARDI, R. A avaliação de livros e materiais didáticos para o ensino de Ciências e as necessidades formativas do docente. In: BICUDO, M. A. V.; SANTANA JUNIOR, C. A. (Org.). Formação do educador e avaliação educacional, v. 4, p. 93-103. São Paulo: Editora Unesp, 1999.

NUÑEZ, I. B. et al. O livro didático para o ensino de Ciências. Selecioná-los: um desafio para os professores do ensino fundamental. In: ENCONTRO NACIONAL DE PESQUISA EM 
EDUCAÇÃO EM CIÊNCIAS, 3., 2001, Atibaia. Anais... Atibaia, 2001. CD-ROM.

QUESADO, M. O papel dos aspectos da natureza da Ciência em livros didáticos de Ciências uma análise textual. In: MARTINS, I.; GÔUVEA, G.; VILANOVA, R. (Org.). O livro didático de Ciências: contexto de exigência, critérios de seleção, práticas de leitura e uso em sala de aula. Rio de Janeiro: FAPERJ, 2012. p. 91-104.

SGNAULIN, I. M. Seleção e uso de livro didático de Ciências por professores iniciantes e experientes, da rede municipal de ensino de Campo Grande, Mato Grosso do Sul. 2012. 146 f. Dissertação (Mestrado em Educação) - Pós-Graduação em Educação, Universidade Católica Dom Bosco, Campo Grande. 2012.

TARDIF, M. Saberes docentes e formação profissional. 13. ed. Petrópolis, Rio de Janeiro: Vozes, 2012.

TOLENTINO-NETO, L. C. B. O processo de escolha dos livros didáticos de Ciências por professores de $1^{\mathrm{a}}$ a $4^{\mathrm{a}}$ séries. 2003. $101 \mathrm{f}$. Dissertação (Mestrado em Educação) -Faculdade de Educação, USP, São Paulo. 2003.

ZAMBON, L. B. Seleção e utilização de Livros Didáticos de Física em Escolas de Educação Básica. 2012. 256 f. Dissertação (Mestrado em Educação) - Centro de Educação, Universidade Federal de Santa Maria, Santa Maria. 2012.

ZAMBON, L. B.; et al. Ações extensionistas de assessoramento na organização do trabalho escolar: materiais e recursos didáticos para o trabalho docente. In: SEMINÁRIO DE EXTENSÃO UNIVERSITÁRIA DA REGIÃo SUL -SEURS, 29., 2011, Foz do Iguaçu. Anais... Londrina: Desafios da Ciência entremeando culturas, 2011. CD-ROM.

Recebido: 17/12/2015

Aprovado: 08/07/2016

Contato:

Marcelo D'Aquino

Faculdade de Educação

Universidade Estadual de Campinas

Rua Bertrand Russell, 801, Cidade Universitária Zeferino Vaz

Cidade Universitária, Campinas - SP, 13083-865 